\title{
Ceasing of muscle function with aging: is it the consequence of intrinsic muscle degeneration or a secondary effect of neuronal impairments?
}

\author{
P. A. Figueiredo • M. P. Mota $\cdot$ H. J. Appell • J. Duarte
}

Received: 21 March 2006 / Accepted: 19 July 2006 / Published online: 22 August 2006

(C) EGREPA 2006

\begin{abstract}
Aging is associated with a significant decline in neuromuscular function leading to an eventual loss of independence and mobility of senescent people. Agerelated sarcopenia, characterised by a reduction in muscle mass and strength, is considered one of the most striking features of aging at the level of the skeletal muscle. Morphological alterations in skeletal muscle can be considered as one of the consequences responsible for muscle weakness in the aged population. Beyond 60 years of age, human muscle undergoes a process of continuous denervation and reinnervation, due to an accelerating loss of motor units. It appears evident that phenotypic alterations in muscle depend on the motor drives provided by the nervous system. Because the peripheral nerves, the neuromuscular junction and motor neurons exhibit degenerative features during advanced age, sarcopenia does not seem to intrinsically develop, but is rather a secondary effect of impaired neuronal function. It is therefore recommended that elderly subjects undergo an exercise program that is aimed towards the improvement of coordinative skills and of muscle strength.
\end{abstract}

P. A. Figueiredo $\cdot$ H. J. Appell $\cdot$ J. Duarte $(\bowtie)$

Faculty of Sports, Centro de Investigação em Actividade Fìsica,

Saúde e Lazer,

R. Dr. Plácido Costa, 91,

4200-450 Porto, Portugal

e-mail: jarduarte@fcdef.up.pt

M. P. Mota

University of Trás-os-Montes and Alto Douro,

Vila Real, Portugal

H. J. Appell

Department of Physiology and Anatomy,

German Sport University,

Cologne, Germany
Keywords Skeletal muscle aging · Sarcopenia . Neuropathy Functional impairment

\section{Introduction}

Aging is an inevitable biological process characterised by the progressive deterioration of numerous physiological functions leading eventually to reductions in functional capacities $[1,11,23,47]$. There is an enormous biological variability in the aging process not only among individuals with similar chronological ages but also among the several organs and systems of the same individual [16]. In fact, the rate of aging varies dramatically between tissues like neural, cardiac, skeletal muscle and other long-living postmitotic cells, becoming dramatically altered during senescence. In contrast, bone marrow cells and other short-living cells undergo only slight or almost undetectable changes $[57,58]$. It is also evident that aging of a particular physiological system will have a deleterious influence on the aging of other physiological systems, so overall aging must be understood and interpreted as a multifactorial process.

In this context, it is believed that skeletal muscle is a tissue with high susceptibility to the aging process $[8,13$, $23,43,52]$, which will inevitably undergo progressive and deleterious changes associated with structural disorganization and functional decline. It is well known that the human aging process is associated with a significant decline in muscular function and physical performance $[10,23,25$, 56]. The reduction in muscle mass and strength with advanced age is considered by many authors $[1,3,8,16$, $23,27,35,47,63]$ to result in dramatic reductions in the functional capacity of the elderly, being probably a frequent and most important cause of ceasing independence and 
mobility in senescence. Age-related morphological alterations in skeletal muscle can be considered responsible for the decrements in muscle strength in aged individuals [2, $29,49,53,63]$. Muscle weakness in the aged muscle is correlated with a loss in muscle mass [23], documented by a decrease in the cross-sectional area of the whole muscle and individual muscle fibres as well as by a reduced number of muscle fibres and declining capillary density $[25,36,44]$. The mechanisms of aging-related sarcopenia are complex and hitherto not completely understood. Whilst it may be considered a part of normal changes within the final third of the human life span [63], it must also be recognised that other factors such as a sedentary lifestyle, inadequate nutrition and diseases deleteriously influence muscle performance $[13,23,52]$. Like the underlying causes of aging, the biology of sarcopenia remains elusive. A number of mechanisms have been proposed in an attempt to explain the changes in total muscle mass and strength with aging. These include a variety of systemic and/or local factors, such as lack of regular physical activity, changes in protein metabolism, with a deficit of protein synthesis vs degradation, alterations in the endocrine milieu, an impairment of neuromuscular function, altered gene expression, deficits in satellite cell recruitment, oxidative stress, agerelated accumulations of mitochondrial abnormalities (e.g., mitochondrial DNA mutations; electron transport system abnormalities) and apoptosis [10, 38].

Whilst the structural alterations observed in old muscles at first glance appear to resemble an intrinsic process of muscle aging, one has to consider that muscle structure and therefore function is triggered extrinsically by the nervous system. Consequently, neuronal alterations occurring in senescence should also contribute substantially to the eventual loss of muscle function at advanced age.

It is a fact that aging is also associated with neurological changes which directly affect voluntary force production [49]. One of the major features of aging in skeletal muscle is the rearrangement of the pattern of innervation. The loss of fast motor neurons leave populations of denervated fibres within the aging muscle, which partly may be compensated by sprouting of the remaining neurons to supply some of the denervated muscle fibres [8]. It is believed that age-related muscle denervation accounts for the muscle weakness encountered in the aged muscle [62]. Considering that motor neurons control muscle growth and fibre type properties by regulating muscle gene expression by local (release of neural factors) and general mechanisms (neuronal electrical activity) [55], it should be suggested that skeletal muscle phenotypic alterations with age are strongly linked to respective alteration of the neural system.

In this review, we will focus our attention mainly on the age-related muscle morphological alterations and their influence on skeletal muscle function, as well as on the age-related morphological and functional alterations at the level of the nervous system.

\section{Aging of skeletal muscle}

Clinical manifestation of muscle aging

It has been demonstrated that total muscle cross sectional area decreases by $\sim 40 \%$ between the ages of 20 and 60 years [21, 43, 63]. Total cross sectional areas have been determined in several limb muscles by various imaging techniques, for example by ultrasound scanning and computed tomography, magnetic resonance imaging (MRI) and direct measurements of whole muscle cross sections in cadaver specimens [23, 36]. For example, Young et al. $[66,67]$ reported 25 to $35 \%$ reductions in the total quadriceps cross sectional area for older (70-79 years old) men and women as compared to young controls (2128 years old).

Age-related decrements in strength have been well documented in multiple cross-sectional studies under isometric and dynamic conditions [23, 43]. Some recent reports are consistent with the fact that healthy people of 70 to 80 years exhibit $20-40 \%$ less strength compared with younger subjects, as assessed during isometric and concentric strength tests of knee extensor muscles [23, 44]. Even greater losses have been reported for subjects in the ninth decade of life ( $50 \%$ or more). These age-related reductions are relatively similar in both sexes, for proximal and distal muscles, and in upper and lower extremities [49]. One peculiar finding is that these decreases are less remarkable during isokinetic eccentric contractions [49]. This could be related to slower contractile properties and increased or altered connective tissue contents and properties favouring the idea of more muscle stiffness in older adults [23].

\section{Morphological changes of muscle fibres}

The decline in total muscle cross sectional area during aging is most likely due to decreases in total fibre number, and to a lesser extent to a reduction in fibre size [36]. There is some variability concerning the reductions in muscle fibre cross sectional area, with values ranging from 20 to $50 \%$ for type II and 1 to $25 \%$, for type I muscle fibres [3, $21,28,32,35,43,49]$. The ranges of variation may be associated with sampling variability, potential sampling biases in muscle biopsies, factors concerning somewhat older or younger control groups and the muscles used for analyses [23, 59]. Moreover, the age-related fibre atrophy is very inhomogeneous when looking at the fibre pool as a whole. In muscle biopsies from very old subjects ( $>85$ years), Andersen [3] observed that in some areas the 


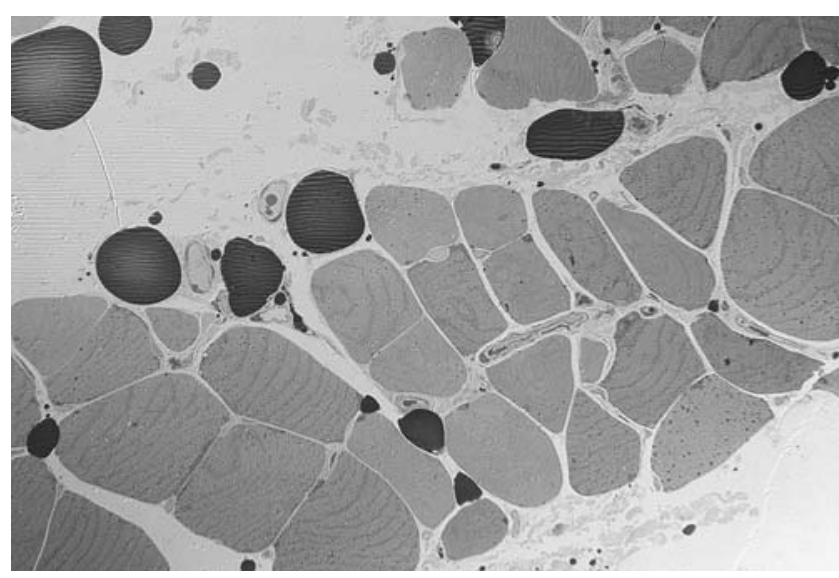

Fig. 1 Light micrograph from a transverse section of gluteus medius of a 65 -year-old woman evidencing several muscle fibres with a great heterogeneity in fibre size and shape. Note also the enlargement of the interstitial space, which is infiltrated by many adipocytes and connective tissue (original magnification: $400 \times$ )

fibres had almost "normal" size, and in their close vicinity, he found areas where the fibres were small, or even extremely small (cf. Fig. 1). Age-related atrophy might be fibre type specific because numerous studies have pointed out that in vastus lateralis, tibialis anterior and biceps brachii muscles, the cross sectional area of type II fibres are significantly reduced with aging, whilst those of type I fibres are less affected [3, 21, 28, 32, 35, 43, 49]. The reductions in fibre size appear moderate compared with the reductions in total muscle volume, suggesting that reductions in muscle fibre number may play a crucial role when considering the gross muscle atrophy with aging [27].

In this matter, the total number in muscle fibres starts to decrease at about 25 years of age and progresses eventually at an accelerated rate [35]. Lexell et al. [35], using whole muscle cross sections from vastus lateralis muscle obtained post-mortem, reported about $50 \%$ less type I and type II fibres by the ninth decade compared with 20 years old controls. So the picture emerges that preferentially type II fibres do atrophy with advanced age, but both fibre types experience losses in numbers more or less equally.

The changes skeletal muscle is undergoing with aging are well documented at the structural and ultrastructural level. In the elderly human muscle, fibres from the vastus lateralis muscle cut transversely exhibit a flattened appearance (cf. Fig. 1), in contrast to the spherical shape of the fibre types from young muscles [3]. This flattening of the fibres is more pronounced among the type II fibres and it was suggested that this change in shape could be the very first sign of a programmed cell death [3]. This may also depend on the pattern of activation. An age-related type II disuse can be assumed because very old people are not subjected to work demanding force and power and therefore do not (or very seldomly) activate a great percentage of type II fibres, thus they slowly atrophy due to lack of stimulation. This is also reflected by the notion that old muscles become slower.

When ultrastructural characteristics of aging rat anterior tibial muscle (35-44 months) were determined [29], a reduction of and abnormalities within the myofibrils were the main causes of atrophy at the cellular level. The myofibrils become thinner and partly desintegrated, and the structure of the sarcomeres becomes incomplete with occasional losses of the Z-line (cf. Figs. 2 and 3). Many of the atrophied fibres demonstrate a condensation and deformation of nuclei, with the nuclear membrane deeply indented (cf. Fig. 4). Some nuclei often appear shrunken and hyperchromatic. Also, a diminished number and size of mitochondria were reported by Kaminska and colleagues [29] in aged rats (cf. Figs. 2, 4 and 5). Lipofuscin is frequently observed (cf. Fig. 4) often accumulating beneath the sarcolemma in moderately and severely atrophied fibres; fragmentation of muscle fibres and alterations in the appearance of the basement membrane are other morphological features described by the above-mentioned authors. Also, in very old rats (27 months old), there is ultrastructural evidence of myofibrillar loss and an increase in intermyofibrillar spaces [33] (cf. Figs. 2 and 5), which is known to influence the specific tension (tension per cross sectional area) during muscle contraction [5].

However, these features are not unequivocally described in the literature. A study on senescent human vastus lateralis muscle [51] did not report any ultrastructural

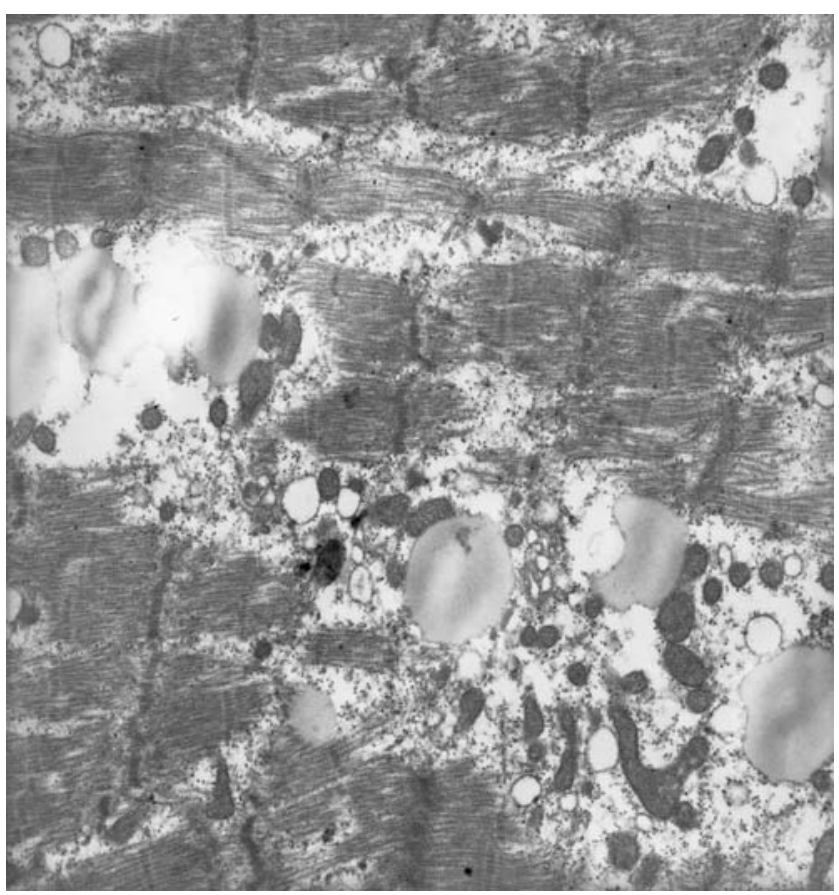

Fig. 2 Transmission electron micrograph from a longitudinal section of the gluteus medius muscle of a 70-year-old man, evidencing several lipid inclusions, small volume mitochondria and myofibril disarrangement (original magnification: $12,500 \times$ ) 


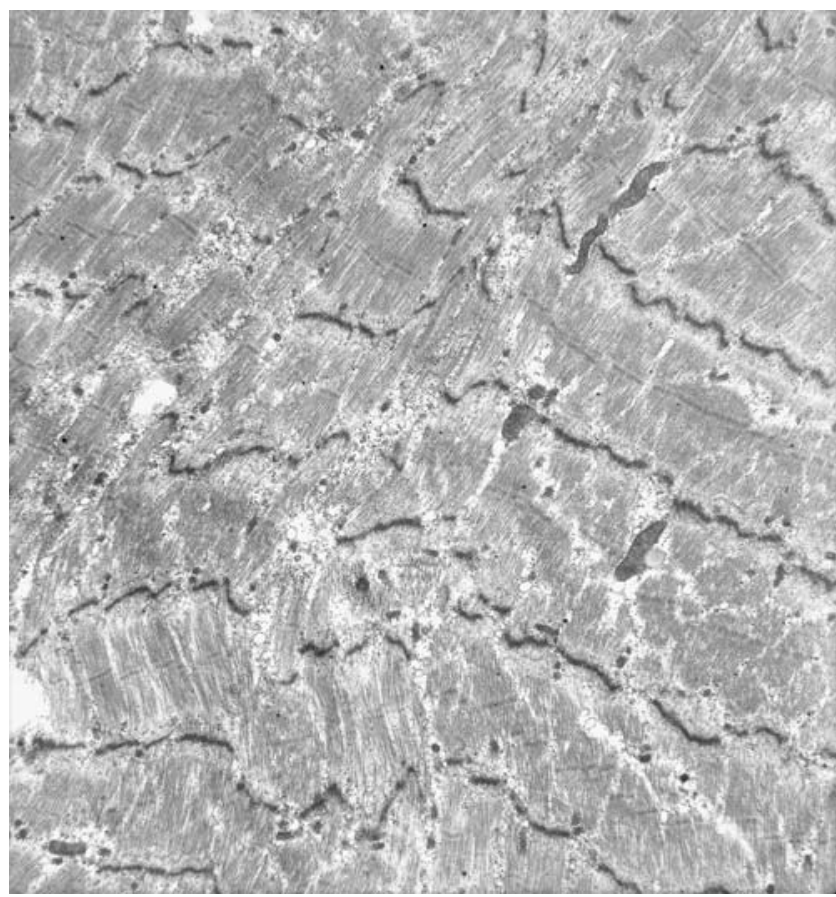

Fig. 3 Transmission electron micrograph of a longitudinal section of the gluteus medius muscle of a 70-year-old man, showing marked alterations of the myofibrillar pattern (original magnification: $8,000 \times$ )

differences between sedentary young and older men. In contrast, the works of Scelsi et al. [54] and Tomonaga [61] suggested that older sedentary individuals exhibited more frequently signs of muscle damage in several muscles, namely, myofibrillar degeneration with Z-line streaming. In elderly men, Andersen [3] and Larsson et al. [33] found an increased incidence of a scalloped appearance of the sarcolemma in muscle fibres expressing fast myosin isoforms. This could be the consequence of a degenerative process which preferentially affects type II muscle fibres [3]. Ansved and Edstrom [5] also reported a pronounced folding of the sarcolemma in aged rat muscles and suggested that this might be related to a decreased calibre of myofibrils in response to a loss of innervation.

\section{Alterations in the interstitial space}

The reduction in muscle cross sectional area with age is accompanied by an augmentation of non-contractile structures in the interstitial space [42, 48]. Rice et al. [48] reported large age-related increases in non-muscle tissue (fat and connective tissue, cf. Figs. 1 and 5) for the arm flexors $(27 \%)$, arm extensors (45\%) and foot plantar flexors (81\%). Overend et al. [42] found reductions in the crosssectional area of the quadriceps (27\%) and hamstrings (18\%) muscles of elderly men (65-77 years old), and concomitant increases in non-muscle tissue of 59\% (quadriceps) and $127 \%$ (hamstrings). This coincidence shows that the reductions in active muscle mass with age are much greater than the data of total muscle cross sectional area suggest.

The findings from animal experiments regarding agerelated changes in capillary density are not unequivocal. The number of capillaries can change because of several factors including development, aging and variations in muscle activity [31]. Most studies did not indicate severe age-related influences on skeletal muscle capillary density $[14,41]$; however, others have reported either a decrease [18] or an increase [17] in skeletal muscle capillary density with aging. Capillary luminal diameter is an important factor in determining the functional potential for peripheral blood flow and supply [31]. Whilst tail-suspended rats show a diminished capillary luminal size in their atrophied muscles [30], there are no significant differences in capillary luminal diameter in old rats, indicating that capillary size remains unaltered in atrophied muscles due to aging [31].

A question that is now emerging is whether the agerelated changes in muscle tissue previously mentioned are due to intrinsic alterations at the level of the muscle fibres themselves or whether at least some of these alterations are the consequence of extrinsic factors resulting from the aging process of other organs and systems.

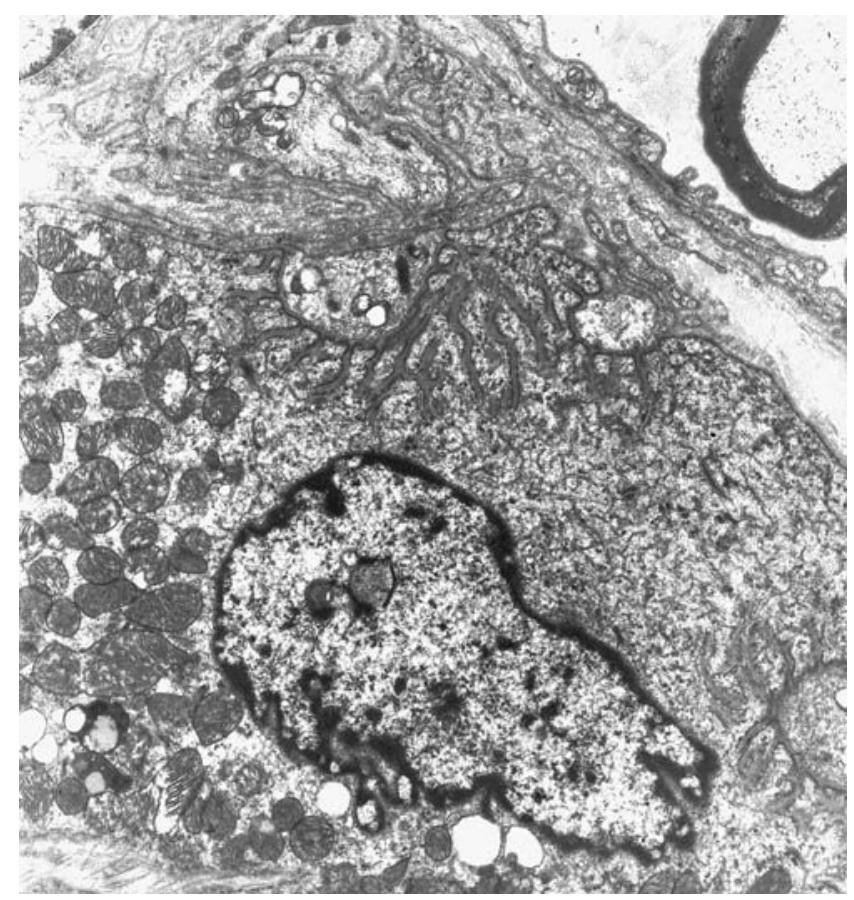

Fig. 4 Transmission electron micrograph from a transversal section of the gluteus medius muscle of a 68-year-old man, illustrating a neuromuscular junction with marked signals of mitochondrial degeneration. The nucleus has a scalloped surface and there are lipofuscin granules between the small mitochondria (original magnification: $5,400 \times)$ 


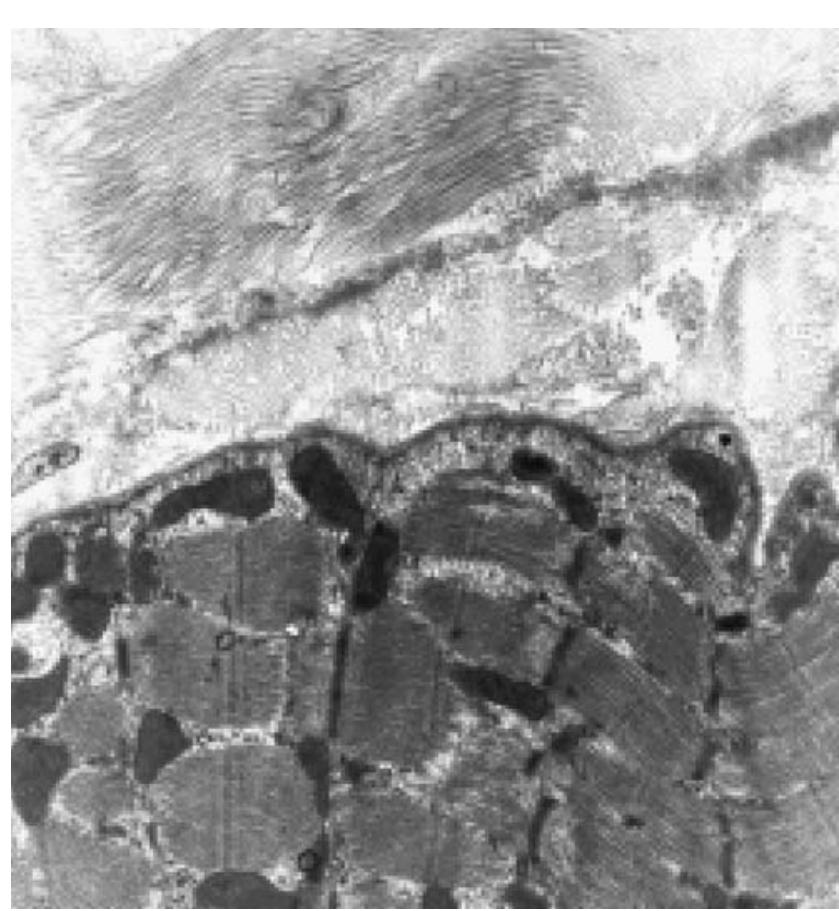

Fig. 5 Transmission electron micrograph from a longitudinal section of the vastus lateralis muscle of a 68 -year-old man, showing a muscle fibre containing condensed mitochondria of small size and the interstitial space enriched with collagen fibres (original magnification: $24,000 \times)$

\section{Aging of motor neurons}

The function of skeletal muscle intimately depends on the central and peripheral nervous system. Motor neurons control muscle contraction through the well-characterised process of excitation-contraction coupling; in addition, motor neurons control muscle growth and fibre type properties by regulating muscle gene expression [55]. These neural effects on skeletal muscle involve two distinct mechanisms; a humoral mechanism mediated by the release of neural factors (e.g. agrin and neuregulin) from the nerve terminals and a neurophysiological mechanism mediated by the pattern of electrical nerve discharge [55]. It is suggested that the control by the electrical activity per se, rather than the release of neural factors, is the predominant mechanism because motor neuron silencing, without any structural interruption of the neuromuscular connections, has dramatic effects on muscle fibre size and fibre type profile, similar to those observed after experimental denervation. Moreover, direct electrostimulation of denervated muscles can prevent muscle atrophy and modulate contractile properties and fibre type profiles, according to the impulse pattern applied [55]. In addition, the loss of specific force found in senescence may partly be explained by a reduced pool of muscle fibres with intact innervation resulting from ageassociated spontaneous denervation [62].
Alterations at the neuromuscular junction

The neuromuscular junction is the synaptic link between motor neurons and muscle fibres [45] and some of the aging-related modifications in neuromuscular activity may result from morphological and physiological alterations at the neuromuscular junction [20]. Some studies have reported an age-related remodelling of the neuromuscular junction in locomotor muscles, such as fragmentation, altered patterns of terminal branching, retraction of nerve terminals and enlarged or denuded postsynaptic areas [15]. When examining age-related ultrastructural alterations in neuromuscular junctions, Wokke et al. [65] found an increased complexity at the postsynaptic side, namely, an increased extension and spreading of the postsynaptic membrane with a concomitant flattening of synaptic folds. Prakash and Sieck [45] found an increased number of nerve terminals in the diaphragm, particularly in type IIx and IIb fibres, and an enlarged end-plate area, which may result from an increased number of nerve terminals. Taken together, these changes are assumed to represent the process of denervation and reinnervation, which may compromise motor drive and should contribute to muscle weakness [45].

The synaptic deterioration observed in aged animals has also been proposed to be partly due to changes in the activity of motor neurons [6, 20]. It is known that alterations in neuronal activity induce morphological and physiological adaptations at the neuromuscular junction. Chronic exercise results in larger pre- and post-synaptic dimensions in the neuromuscular junction [4, 19], and complete muscular disuse by denervation elicits morphological patterns of remodelling, like nerve terminal sprouting and expansion of the endplate [46]. Muscle unloading in aged rats leads also to a marked morphological remodelling of synaptic contact zones with increased numbers of presynaptic vesicles [20] (cf. Fig. 6). These structural findings might be interpreted as a yet obsolete attempt to compensate for insufficient motor drives towards the aging muscle fibres.

Motor unit enlargement by sprouting of new nerve terminals is an important compensatory mechanism against the loss of working motor units during aging and also in neuromuscular diseases [26]. With advanced age, an increased instability of motor innervation occurs, which has been established in the muscles of mice older than 15 months [7]. This instability could be the result of a loss of terminal branches of the motor nerve and of a reduced density of postsynaptic acetylcholine receptors. At $12-$ 18 months of age (in mice), the motor neurons appear to compensate some of the eventual losses of synaptic sites by sprouting and thereby adding new sites; however, this compensatory addition appears to decrease dramatically 


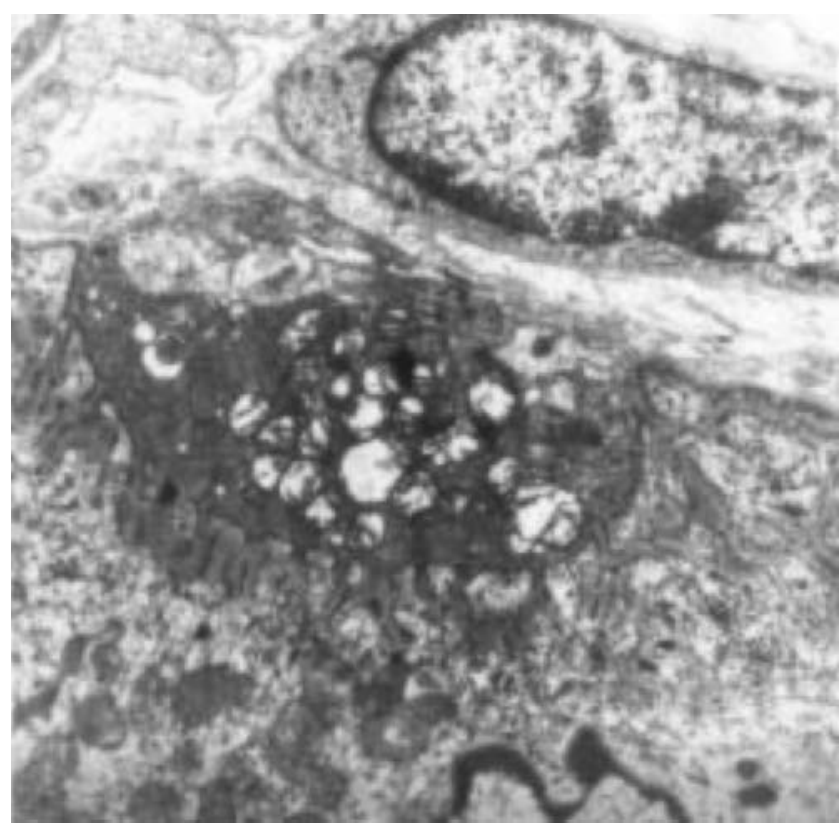

Fig. 6 Transmission electron micrograph of the neuromuscular junction in soleus muscle of an old rat showing degenerating mitochondria and a very high density of synaptic vesicles (original magnification: $24,000 \times$ )

with age. At 24-36 months, the vast majority of neuromuscular junctions in the sternomastoid muscle of mice [6] undergo significant losses of pre- and post-synaptic sites. This coincides with an increased incidence of synaptic transmission failure towards the muscle fibres when the motor nerves are stimulated at relatively low frequencies (10 to $20 \mathrm{~Hz}$ ).

\section{Motor unit remodelling}

Fibre type grouping has become evident in a number of studies examining either whole muscle preparations or muscle biopsies of elderly subjects [3, 24, 34]. Grouping describes the phenomenon that fibres of identical type seem to concentrate in clusters rather than being distributed in the random fashion commonly observed in younger muscles [3]. According to Andersen [3], the mechanisms for grouping of the fibre types in aging human muscle still need to be completely clarified. However, the most intriguing explanation seems to be that fibre type grouping arises from a continuous process of denervation and partial reinnervation that is claimed to accelerate with advanced aging and is secondary to a chronic neuropathic process. This may reach a phase where the compensatory reinnervation does not keep pace anymore with the denervation and thereby muscle fibres or even complete motor units get lost, subsequently being replaced by fat and fibrous tissue [36]. This could explain why muscles from elderly individuals comprise a much smaller portion of parenchy- mal tissue and a much higher portion of stromal fat or connective tissue than younger controls [35, 48].

One of the major features of aging skeletal muscle is the rearrangement of the innervation. Motor unit remodelling corresponds to the natural cycle of synaptic turnover at the neuromuscular junction by the process of denervation, axonal sprouting and reinnervation of muscle fibres [9]. During aging, type II fibres are selectively denervated and reinnervated by collateral sprouting of axons belonging to slow motor units, which might result from their faster axonal growth or their superiority in establishing permanent connections with both type I and type II muscle fibres [8, 49], thereby eventually changing the contractile characteristics of the latter ones. According to Carmeli and Reznick [12] this theory can account for many of the observed functional and morphological changes in skeletal muscle, especially the well known age-related slowing of muscles.

Observations reported in the literature show that the morphological alterations of motor units are consistent with a chronic neuropathic process $[21,22]$. The most evident change is a decrease in the total number of motor units [21]. Loss of motor units has been estimated to amount $1 \%$ of their total number per year, beginning during the third decade of life and increasing rapidly in rate beyond the age of 60 [49]. This, however, is not accompanied by an equal loss of muscle fibres; therefore, each motor neuron innervates more muscle fibres in the aged than in younger muscles [49]. This has been shown indirectly by EMG techniques documenting an increase in motor unit size in the vastus lateralis, tibialis anterior and biceps brachii muscles from subjects older than 60 years (reviewed by [63]). Based on experiments in senescent rats, there is a general consensus that age related reductions in the number of motor units range from $40-75 \%$ with greater losses among the largest motor units with the lowest oxidative capacities (reviewed by [21]). These results are in accordance with the phenomenon of fibre grouping and suggest an early preferential degeneration of the fast motor units with age [21].

The number of excitable motor units is considered to be reduced with advanced age, particularly in the seventh decade of life [22]. This has so far been explained with mechanisms within the peripheral nervous system. The question arises as to whether also a loss of motor neurons appears in the spinal cord.

Tomlinson and Irving [60] have estimated the number of motor neurons in the lumbosacral segments (L1-S3) of 47 individuals aged 13-95 years; their findings suggest an average loss of motor neurons from the second to tenth decade of life of approximately $25 \%$, and several subjects above 60 years even had only half the number of motor units young or middle-aged adults had. The loss of motor neurons is accompanied by a reduction in both, numbers 
and diameters of motor axons in the ventral roots [37]. Functionally, the integrity of the peripheral motor system is often assessed by measuring the maximal motor conduction velocity of a given nerve. Axonal conduction velocity decreases with age presumably reflecting a variety of changes in the nerve fibres, such as a dropout of the largest and fastest conducting motor fibres, segmental demyelination and reduced internodal length [22, 64]. This progressive loss and/or related dysfunction of motor nerves should play an important role in muscle aging and atrophy. It should also be noted that although nerve cells may still remain existing in aged people, they become dysfunctional because of accumulating biochemical changes shown by the presence of lipofuscin, which does apparently precipitate during neuronal degeneration $[21,40]$. Lipofuscin is a pigment derived from oxidation of lipids or lipoproteins and is accepted to be the most reliable and widespread cytological sign correlated with neuronal aging [21].

\section{Concluding remarks}

Although the mechanisms for age-related decline in skeletal muscle mass and function still remain to be fully understood in many details, the functional consequences of sarcopenia are well known. These include muscle weakness, a reduced endurance capacity and an increased fatigability resulting in an eventual loss of mobility, independence and in increased fragility in many older adults [38, 50, 53].

Considering all the above referred findings, it is suggested that skeletal muscle morphological and functional alterations with age do not only result from intrinsic factors within the muscle fibres but are also influenced by aging phenomena of the nervous system, especially of its peripheral components. In this sense, the alterations found in muscle fibres represent secondary effects based on the aging process of the nervous system.

This concept should not only be useful to explain eventual losses in strength encountered at advanced age, but should also explain the increased inability of elderly subjects to perform properly simple tasks of daily life. A loss of motor units and concomitantly larger motor units lead to an impairment of coordination in general. Moreover, alterations found in peripheral nerves and at the neuromuscular junction might incline the neuromuscular system to impairments in reflex responses necessary for, e.g. maintenance of posture and balance. These impaired coordinative skills frequently result in an increased susceptibility to fall among elderly subjects. It therefore should be a preventive challenge to subject the elderly to a mild exercise program with the aim to improve muscle strength and especially coordination.
In this matter, it seems reasonable to expect that interventions aimed to retard or prevent the loss of skeletal muscle mass and strength with age, like physical activity, should exert a major influence on neural adaptations. In fact, bearing in mind that aged skeletal muscle has a reduced adaptative potential [47] with a diminished number and reduced proliferative capacity of satellite cells [59], we can assume that the benefits of physical activity in the aged muscle, particularly strength training, are probably and mainly due to neural adaptations which might retard or prevent the consequences of the aging process primarily at the level of the nervous system, with beneficial secondary effects on the functional properties of skeletal muscle.

In addition, age-related alterations of skeletal muscle are accompanied by decreases in the metabolic rate, bone density and insulin sensitivity [39]. For these reasons, strategies for preserving muscle mass with advancing age should not only be important to maintain functional independence, but also to prevent some age associated chronic diseases.

Acknowledgement This work was supported by POCI 2010 s

Ciência.Inovação Programa Operacional Ciência e Inovação 2010 and 2010 Programa Operacional Ciencia e Inovaçăo

FSE

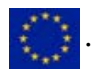

\section{References}

1. Adhihetty P, Hood D (2003) Mechanisms of apoptosis in skeletal muscle. Basic Appl Myol 13(4):171-179

2. Akataki K, Mita K, Watakabe M, Ito K (2002) Age-related change in motor unit activation strategy in force production: a mechanomyographic investigation. Muscle Nerve 25(4):505-512

3. Andersen JL (2003) Muscle fibre type adaptation in the elderly human muscle. Scand J Med Sci Sports 13(1):40-47

4. Andonian MH, Fahim MA (1987) Effects of endurance exercise on the morphology of mouse neuromuscular junctions during ageing. J Neurocytol 16(5):589-599

5. Ansved T, Edstrom L (1991) Effects of age on fibre structure, ultrastructure and expression of desmin and spectrin in fast- and slow-twitch rat muscles. J Anat 174:61-79

6. Balice-Gordon RJ, Lichtman JW (1993) In vivo observations of pre- and postsynaptic changes during the transition from multiple to single innervation at developing neuromuscular junctions. J Neurosci 13(2):834-855

7. Balice-Gordon RJ (1997) Age-related changes in neuromuscular innervation. Muscle Nerve (Suppl 5):S83-S87

8. Booth FW, Weeden SH, Tseng BS (1994) Effect of aging on human skeletal muscle and motor function. Med Sci Sports Exerc 26(5):556-560

9. Brooks SV, Faulkner JA (1994) Skeletal muscle weakness in old age: underlying mechanisms. Med Sci Sports Exerc 26(4):432439

10. Bua EA, McKiernan SH, Wanagat J, McKenzie D, Aiken JM (2002) Mitochondrial abnormalities are more frequent in muscles undergoing sarcopenia. J Appl Physiol 92(6):2617-2624 
11. Calleja M, Pena P, Ugalde C, Ferreiro C, Marco R, Garesse R (1993) Mitochondrial DNA remains intact during Drosophila aging, but the levels of mitochondrial transcripts are significantly reduced. J Biol Chem 268(25):18891-18897

12. Carmeli E, Reznick AZ (1994) The physiology and biochemistry of skeletal muscle atrophy as a function of age. Proc Soc Exp Biol Med 206(2):103-113

13. Carmeli E, Coleman R, Reznick AZ (2002) The biochemistry of aging muscle. Exp Gerontol 37(4):477-489

14. Cartee GD (1994) Aging skeletal muscle: response to exercise. Exerc Sport Sci Rev 22:91-120

15. Courtney J, Steinbach JH (1981) Age changes in neuromuscular junction morphology and acetylcholine receptor distribution on rat skeletal muscle fibres. J Physiol 320:435-447

16. Cristofalo VJ, Gerhard GS, Pignolo RJ (1994) Molecular biology of aging. Surg Clin North Am 74(1):1-21

17. Davidson YS, Clague JE, Horan MA, Pendleton N (1999) The effect of aging on skeletal muscle capillarization in a murine model. J Gerontol A Biol Sci Med Sci 54(10):B448-B451

18. Degens H, Ringnalda BE, Hoofd LJ (1994) Capillarisation, fibre types and myoglobin content of the dog gracilis muscle. Adv Exp Med Biol 361:533-539

19. Deschenes MR, Maresh CM, Crivello JF, Armstrong LE, Kraemer WJ, Covault J (1993) The effects of exercise training of different intensities on neuromuscular junction morphology. J Neurocytol 22(8):603-615

20. Deschenes MR, Wilson MH (2003) Age-related differences in synaptic plasticity following muscle unloading. J Neurobiol 57 (3):246-256

21. Doherty TJ, Vandervoort AA, Brown WF (1993) Effects of ageing on the motor unit: a brief review. Can J Appl Physiol 18(4):331358

22. Doherty TJ, Vandervoort AA, Taylor AW, Brown WF (1993) Effects of motor unit losses on strength in older men and women. J Appl Physiol 74(2):868-874

23. Doherty TJ (2003) Invited review: aging and sarcopenia. J Appl Physiol 95(4):1717-1727

24. Essen-Gustavsson B, Borges O (1986) Histochemical and metabolic characteristics of human skeletal muscle in relation to age. Acta Physiol Scand 126(1):107-114

25. Frontera WR, Hughes VA, Fielding RA, Fiatarone MA, Evans WJ, Roubenoff R (2000) Aging of skeletal muscle: a 12-yr longitudinal study. J Appl Physiol 88(4):1321-1326

26. Gordon T, Hegedus J, Tam SL (2004) Adaptive and maladaptive motor axonal sprouting in aging and motoneuron disease. Neurol Res 26(2):174-185

27. Grimby G, Saltin B (1983) The ageing muscle. Clin Physiol 3 (3):209-218

28. Grimby G, Aniansson A, Zetterberg C, Saltin B (1984) Is there a change in relative muscle fibre composition with age? Clin Physiol 4(2):189-194

29. Kaminska AM, Fidzianska A, Schulze G, Coper H, Ossowska K, Wolfarth S, Hausmanowa-Petrusewicz I (1998) Ultrastructural changes in the skeletal muscle of senile rats with significant agedependent motor deficits. Basic Appl Myol 3(3):185-190

30. Kano Y, Shimegi S, Takahashi H, Masuda K, Katsuta S (2000) Changes in capillary luminal diameter in rat soleus muscle after hind-limb suspension. Acta Physiol Scand 169(4):271-276

31. Kano Y, Shimegi S, Furukawa H, Matsudo H, Mizuta T (2002) Effects of aging on capillary number and luminal size in rat soleus and plantaris muscles. J Gerontol A Biol Sci Med Sci 57(12): B27-B422

32. Klein CS, Marsh GD, Petrella RJ, Rice CL (2003) Muscle fiber number in the biceps brachii muscle of young and old men. Muscle Nerve 28(1):62-68
33. Larsson L, Li X, Yu F, Degens H (1997) Age-related changes in contractile properties and expression of myosin isoforms in single skeletal muscle cells. Muscle Nerve (Suppl 5):S74-S78

34. Lexell J, Downham D, Sjostrom M (1986) Distribution of different fibre types in human skeletal muscles. Fibre type arrangement in $\mathrm{m}$. vastus lateralis from three groups of healthy men between 15 and 83 years. J Neurol Sci 72(2-3):211-222

35. Lexell J, Taylor CC, Sjostrom M (1988) What is the cause of the ageing atrophy? Total number, size and proportion of different fiber types studied in whole vastus lateralis muscle from 15- to 83-year-old men. J Neurol Sci 84(2-3):275-294

36. Lexell J (1993) Ageing and human muscle: observations from Sweden. Can J Appl Physiol 18(1):2-18

37. Lexell J (1997) Evidence for nervous system degeneration with advancing age. J Nutr 127(5 Suppl):1011S-1013S

38. Marcell T (2003) Sarcopenia: causes, consequences and preventions. J Gerontol Med Sci 58A(10):911-916

39. Mazzeo RS, Cavanagh P, Evans W, Fiatarone MA, Hagberg JM, McAuley E, Startzell J (1998) Exercise and physical activity for older adults. Med Sci Sports Exerc 30(6):992-1008

40. McComas AJ (1996) Skeletal Muscle. Human Kinetics, Champaign, IL

41. Mitchell ML, Byrnes WC, Mazzeo RS (1991) A comparison of skeletal muscle morphology with training between young and old Fischer 344 rats. Mech Ageing Dev 58(1):21-35

42. Overend TJ, Cunningham DA, Kramer JF, Lefcoe MS, Paterson DH (1992) Knee extensor and knee flexor strength: crosssectional area ratios in young and elderly men. J Gerontol 47(6): M204-M210

43. Porter MM, Vandervoort AA, Lexell J (1995) Aging of human muscle: structure, function and adaptability. Scand J Med Sci Sports 5(3):129-142

44. Porter MM (2001) The effects of strength training on sarcopenia. Can J Appl Physiol 26(1):123-141

45. Prakash YS, Sieck GC (1998) Age-related remodeling of neuromuscular junctions on type-identified diaphragm fibers. Muscle Nerve 21(7):887-895

46. Prakash YS, Miyata H, Zhan WZ, Sieck GC (1999) Inactivityinduced remodeling of neuromuscular junctions in rat diaphragmatic muscle. Muscle Nerve 22(3):307-319

47. Proctor DN, Balagopal P, Nair KS (1998) Age-related sarcopenia in humans is associated with reduced synthetic rates of specific muscle proteins. J Nutr 128(2 Suppl):351S-355S

48. Rice CL, Cunningham DA, Paterson DH, Lefcoe MS (1989) Arm and leg composition determined by computed tomography in young and elderly men. Clin Physiol 9(3):207-220

49. Roos MR, Rice CL, Vandervoort AA (1997) Age-related changes in motor unit function. Muscle Nerve 20(6):679-690

50. Rooyackers OE, Adey DB, Ades PA, Nair KS (1996) Effect of age on in vivo rates of mitochondrial protein synthesis in human skeletal muscle. Proc Natl Acad Sci USA 93(26): 15364-15369

51. Roth SM, Martel GF, Ivey FM, Lemmer JT, Tracy BL, Hurlbut DE, Metter EJ, Hurley BF, Rogers MA (1999) Ultrastructural muscle damage in young vs. older men after high-volume, heavyresistance strength training. J Appl Physiol 86(6):1833-1840

52. Roubenoff R (2001) Origins and clinical relevance of sarcopenia. Can J Appl Physiol 26(1):78-89

53. Sakakima H, Yoshida Y, Suzuki S, Morimoto N (2004) The effects of aging and treadmill running on soleus and gastrocnemius muscle morphology in the senescence-accelerated mouse (SAMP1). J Gerontol A Biol Sci Med Sci 59(10):1015-1021

54. Scelsi R, Marchetti C, Poggi P (1980) Histochemical and ultrastructural aspects of $\mathrm{m}$. vastus lateralis in sedentary old people (age 65-89 years). Acta Neuropathol (Berl) 51(2):99-105 
55. Schiaffino S, Murgia M, Serrano AL, Calabria E, Pallafacchina G (1999) How is muscle phenotype controlled by nerve activity? Ital J Neurol Sci 20(6):409-412

56. Schrager M, Bandinelli S, Maggi S, Ferruci L (2003) Sarcopenia: twenty open questions for a research agenda. Basic Appl Myol 13 (4):203-208

57. Terman A, Brunk UT (2004) Myocyte aging and mitochondrial turnover. Exp Gerontol 39(5):701-705

58. Terman A, Brunk UT (2004) Aging as a catabolic malfunction. Int J Biochem Cell Biol 36(12):2365-2375

59. Thornell LE, Lindstrom M, Renault V, Mouly V, Butler-Browne GS (2003) Satellite cells and training in the elderly. Scand J Med Sci Sports 13(1):48-55

60. Tomlinson BE, Irving D (1977) The numbers of limb motor neurons in the human lumbosacral cord throughout life. J Neurol Sci 34(2):213-219

61. Tomonaga M (1977) Histochemical and ultrastructural changes in senile human skeletal muscle. J Am Geriatr Soc 25(3):125-131
62. Urbanchek MG, Picken EB, Kalliainen LK, Kuzon WM Jr (2001) Specific force deficit in skeletal muscles of old rats is partially explained by the existence of denervated muscle fibers. J Gerontol A Biol Sci Med Sci 56(5):B191-197

63. Vandervoort AA (2002) Aging of the human neuromuscular system. Muscle Nerve 25(1):17-25

64. Wang FC, de Pasqua V, Delwaide PJ (1999) Age-related changes in fastest and slowest conducting axons of thenar motor units. Muscle Nerve 22(8):1022-1029

65. Wokke JH, Jennekens FG, van den Oord CJ, Veldman H, Smit LM, Leppink GJ (1990) Morphological changes in the human end plate with age. J Neurol Sci 95(3):291-310

66. Young A, Stokes M, Crowe M (1984) Size and strength of the quadriceps muscles of old and young women. Eur J Clin Invest 14 (4):282-287

67. Young A, Stokes M, Crowe M (1985) The size and strength of the quadriceps muscles of old and young men. Clin Physiol 5(2): $145-154$ 